DR. MARCO FESTA-BIANCHET (Orcid ID : 0000-0002-2352-3379)

3

4

6

7

Article type : Articles

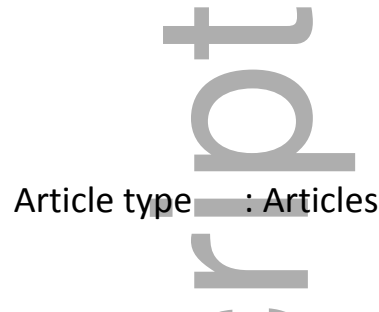

Article type: Article

Running head: Seasonal mass changes in bighorn sheep

\section{Drivers and demographic consequences of seasonal mass changes in an alpine ungulate}

${ }^{1}$ Département de biologie et Centre d'Études Nordiques, Université de Sherbrooke, Sherbrooke, QC, Canada J1K 2R1.

*Corresponding author: mathieu.douhard@gmail.com

Abstract. We know little about the determinants and demographic consequences of the marked seasonal mass changes exhibited by many northern and alpine mammals. We analysed 43 years of data on individual winter mass loss (the difference between mass in early June and mass in mid-September the previous year) and summer mass gain (the difference between mass in midSeptember and in early June of the same year) in adult bighorn sheep (Ovis canadensis). We calculated relative seasonal mass change as a proportion of individual body mass at the start of each season. We first examined the effects of weather and population density on relative changes in body mass. We then assessed the consequences of relative seasonal mass changes on reproduction. Mean April-May temperature was the main driver of relative seasonal mass

This is the author manuscript accepted for publication and has undergone full peer review but has not been through the copyediting, typesetting, pagination and proofreading process, which may lead to differences between this version and the Version of Record. Please cite this article as doi: $\underline{10.1002 / \text { ecy. } 2141}$

This article is protected by copyright. All rights reserved 
changes: warm springs reduced both relative winter mass loss and summer mass gain of both sexes, likely partially due to a trade-off between growth rate of plants and duration of access to high-quality forage. Because these effects cancelled each other, spring temperature did not influence mass in mid-September. Mothers that lost relatively more mass during the winter had lambs that gained less mass during summer, likely because these females allocated fewer resources to lactation. Winter survival of lambs increased with their summer mass gain. In males, relative mass loss during winter, which includes the rut, did not influence the probability of siring at least one lamb, possibly indicating that greater mating effort did not necessarily translate into greater reproductive success. Our findings improve our understanding of how weather influences recruitment and underline the importance of cryptic mechanisms behind the effects of climate change on demographic traits.

Keywords: bighorn sheep, body mass, capital breeder, climate change, nutrition, primary production, reproductive allocation, seasons, weather.

\section{INTRODUCTION}

For the third consecutive year, Earth reached a new heat record in 2016 (NOAA 2017). Ongoing warming is clear in the trend of average global temperature over the past several decades (IPCC 2014). Climate change affects distribution and number of many plant and animal populations (Walther et al. 2002). Many recent studies have investigated the potential impacts of climate change using niche models (Anderson 2013) or by determining how demographic parameters such as reproduction and survival or population growth vary in response to weather variables (Grosbois et al. 2008, Hansen et al. 2013, Selwood et al. 2015). More effort is now required to identify and understand the mechanisms behind demographic responses to climate change.

One way to improve our mechanistic understanding of how climate change influences vertebrate demography is to quantify links between weather, morphological traits and demographic parameters (Tafani et al. 2013, Albon et al. 2017). Body mass has strong ecological implications (Peters 1983) and shapes variation in life-history traits both at the interspecific and the intraspecific levels (Calder 1984, Stearns 1992). In vertebrates, individual mass is generally positively associated with reproductive success or survival (Stearns 1992). For example in Soay sheep (Ovis aries), variation in body mass accounted for one-fifth of observed population growth 
in some years (Pelletier et al. 2007a). Mass typically mediates the influence of density and weather on population dynamics of large mammalian herbivores (Gaillard et al. 2000, Bonenfant et al. 2009). However, body mass integrates skeletal size and body condition, which may differentially influence reproductive success and respond to different selective pressures (FestaBianchet 1998, Toïgo et al. 2006). Body condition reflects short-term changes in muscle mass and fat reserves (Dobson 1992), which are expected to be very important in capital breeders that rely on stored reserves for reproduction (Stephens et al. 2009). Although methods exist to measure fat and protein reserves (see Cook et al. 2001, Milner et al. 2003, Monteith et al. 2013 for case studies), the potential importance of body condition can be quantified indirectly by analysing seasonal mass changes (Van Beest and Milner 2013). Interestingly, winter mass loss of female moose (Alces alces) explained variation in calving rate and recruitment better than absolute mass in early or late winter (Milner et al. 2013).

The study of seasonal changes in body mass is important to understand the impacts of climate change, as responses to global warming can vary across seasons (Altwegg and Anderson 2009, Albon et al. 2017). For example, in female Svalbard reindeer (Rangifer tarandus platyrhynchus), warm summer temperature increased summer mass gain whereas 'rain-on-snow' events, which are expected to intensify over time (Hansen et al. 2014), increased winter mass loss (Albon et al. 2017). These patterns, however, emerged from changes in mass calculated at the population level, and thus cannot account for individual variation (Monteith et al. 2013) and selective disappearance (a change in the population mean of a phenotypic trait due to mortality, Rebke et al. 2010). Identifying the environmental drivers and understanding the demographic consequences of seasonal mass changes measured at the individual level requires repeated measurements of marked individuals, which are rarely available in the wild especially for large vertebrates.

Here we analyse 43 years of data on individual winter mass loss and summer mass gain in adult bighorn sheep (Ovis canadensis) at Ram Mountain, Alberta, Canada. This species faces strong seasonality in weather and, hence, in the quality and availability of resources. Climate change is predicted to be particularly pronounced in highly seasonal environments such as the artic or temperate mountains (Root and Hughes 2005). Bighorn sheep accumulate nutritional 
availability and quality of food causes considerable mass loss. Summer mass gain (the difference in mass between mid-September and early June, Fig. 1) in adult females averages $30 \%$ of June mass, while winter mass loss (the difference between mass in early June mass and in midSeptember the previous year, Fig. 1) averages $~ 20 \%$ of mid-September mass (Festa-Bianchet et al. 1996).

We first investigated whether weather and population density influence relative seasonal changes in mass (absolute mass change accounting for initial mass) of both sexes. Based on previous studies (Portier et al. 1998, Douhard et al. 2017), we expected temperature in the spring months of April and May to be the most important weather variable influencing annual variation in relative winter mass loss and summer mass gain. Individuals should benefit from warm springs by losing less mass in April-May and gaining more mass in the following summer. The sensitivity of relative seasonal mass changes to spring temperature may nevertheless vary between the sexes because of sex-specific constraints imposed by reproduction. Energetic demands for female ungulates in temperate regions are particularly high during spring, which coincides with late gestation and early lactation (Parker et al. 2009). In contrast, the most energetically demanding period for males is the rut, which occurs during autumn in temperate regions (Bobek et al. 1990, Pelletier 2005). Mature males typically deplete body reserves during the rut, and often enter the winter in poor condition (McCullough 1999). Because we expected rams to have little mass to lose after the rut (Pelletier 2005), relative winter mass loss of females should be more influenced than that of males by spring temperature.

We then evaluated the reproductive consequences of relative seasonal mass changes, and compared them with those of mid-September mass in both sexes. Because of the timing of captures, we restricted these analyses to females whose lambs survived the neonatal period (see material and methods). We considered summer and winter survival of lambs separately to identify the most critical period for impact of maternal mass changes on reproduction. Lamb mortality is 3 times greater in winter than in summer (Portier et al. 1998). We also tested the effect of relative winter mass loss of mothers on summer mass gain of lambs (a measure of maternal reproductive effort during lactation, Martin and Festa-Bianchet 2010). Because females that lost more mass during winter must gain more mass during the following summer (Pelletier et al. 2007b), and because mothers favor their own summer mass gain over the growth of their 
113 lambs (Festa-Bianchet and Jorgenson 1998), we predicted that lamb summer mass gain should be

114 lower for mothers that lost relatively more mass during the previous winter. As winter survival of 115 lambs increased with their summer mass gain (Martin and Festa-Bianchet 2010), we predicted 116 that maternal winter mass loss should lead to increased lamb mortality the following winter.

117 Because heavy female mammals generally produce heavy offspring which show high survival 118 rates (Ronget et al. in press, see Clutton-Brock et al. 1996, Griffin et al. 2011 for case studies), 119 we expected that lamb survival should increase with mid-September maternal mass. In male 120 ungulates, relative mass loss during the rut should be related to mating effort (Yoccoz et al. 121 2002, Mysterud 2004, Mysterud et al. 2005). However, greater mating effort does not necessarily

122 imply greater mating success (McElligott et al. 2003, Festa-Bianchet 2012). Consequently, we 123 tested whether the probability of siring at least one lamb was higher for males that lost relatively 124 more mass during the winter.

125

126

127

128

129

130

131

132

133

134

135

136

137

138

139

140

141

\section{MATERIAL AND METHODS}

\section{Study area and population}

Ram Mountain is located about $30 \mathrm{~km}$ east of the Rockies in Alberta, Canada $\left(52^{\circ} \mathrm{N}, 115^{\circ} \mathrm{W}\right.$, elevation 1700-2200 m). The study area covers about $38 \mathrm{~km}^{2}$ of alpine and subalpine habitat (for details, see Jorgenson et al. 1993). The climate is characterized by long, cold winters and short, cool summers. Snowfalls are possible in any month. Since 1973, the population has been closely monitored each year between late May and late September. Sheep are repeatedly captured in a corral trap baited with salt, and more than $98 \%$ are marked with ear tags and visual collars. In most years, over $80 \%$ of the lambs that survive to weaning are captured and marked during their first summer. Age at first capture for lambs varies from 1 week to 4 months but most are captured within a few weeks of birth, which usually occurs in late May or early June (Feder et al. 2008). The rut is generally from mid-November to early December (Pelletier 2005). All unmarked lambs that survive the winter are marked the following year as yearlings. Annual resighting probabilities are over $99 \%$ and $96 \%$ for adult females and males respectively (Jorgenson et al. 1997). There has never been an individual not seen as a yearling but later resighted.

\section{Reproductive data}

This article is protected by copyright. All rights reserved 
142 Female reproductive status was determined by udder examination at capture and field

143 observations of suckles. Since 1988, we genotyped tissue samples to determine paternity

144 (Coltman et al. 2002). Paternities of lambs that died before capture were unknown. Genetic data

145 were also used to confirm behavioral maternity assignments and identify mothers of individuals

146 first captured as yearlings. We classified adult females into six mutually exclusive categories of

147 reproductive status: (1) "no lactation", no evidence of lactation (no milk or colostrum, flaccid

148 udder) in late May or early June; (2) "neonatal mortality", milk or colostrum was expressed at

149 capture but no lamb was seen; (3) "summer loss", the lamb was seen but died before late

150 September, the approximate time of weaning; (4) "winter loss", the lamb died between late

151 September and late May the following year; (5) "lamb survived to 1 year of age"; (6) "lamb

152 winter survival unknown", the lamb survived to weaning but may or may not have survived to 1

153 year. This latter group includes females whose lambs were unmarked and born before 1987, and

154 it was relatively small (5\% compared to $15 \%, 17 \%, 9 \%, 20 \%$ and $34 \%$ for categories 1, 2, 3, 4, 155 and 5).

We refer to adults as individuals aged $\geq 3$ years. Most females start reproducing at 3 years (Martin and Festa-Bianchet 2012), and at that age males first attain a reproductive success of at least $10 \%$ of that of the most successful age class (Festa-Bianchet 2012).

\section{Body mass data}

We measured mass at each capture unless the individual had been weighed less than 3 weeks earlier. Capture success varied with sex-age class, but each summer approximately $85 \%$ of

162 sheep were captured at least once and > $75 \%$ between 2 and 9 times (Martin and Pelletier 2011).

163 To account for differences in capture date, we adjusted individual mass to June 5 (except for 164 lambs, whose mass was adjusted to June 15 as some were born after June 5) and September 15. 165 The mass of adults on September 15 and June 5 was respectively close to the yearly maximum 166 and minimum, although seasonal gain probably begins in May (Festa-Bianchet et al. 1996). Mass 167 adjustment method depended on whether an animal was weighed once or more in a summer. For 168 individuals sampled multiple times, we used linear mixed models with restricted maximum 169 likelihood (REML) with mass at capture as the response variable, capture date (considering May 17025 as day 1) as a fixed effect and sheep identity as well as the interaction between identity and 171 date of capture as random effects (Martin and Pelletier 2011). Because adults gain mass 172 asymptotically during summer (Festa-Bianchet et al. 1996), the square root of capture date was 
173 fitted to linearize the relationship between mass and capture date. Lambs gain mass linearly

174 during summer. We fitted separate linear mixed models for each year and for each category

175 (lambs, adult males and females) and used the predicted values of individual intercepts and

176 slopes (growth rates) to adjust individual mass. For individuals weighed once in a year, we used

177 age-and sex-specific linear models of body mass on capture date to adjust individual mass to

178 June 5/15 or September 15. This latter method was only employed in $11 \%$ of cases because of

179 the high capture rate, and excluded sheep not weighed within 50 days of either adjustment date

180 (Festa-Bianchet et al. 1996).

Henceforth, we refer to mass adjusted to June 5/15 and September 15 as spring and autumn

182

183

184

185

186

187

188

189

190

191

192

193

194

195

196

197

198

199

200

201

202

203

mass, respectively. We calculated absolute summer mass gain as the difference between autumn and spring mass in year t. Absolute winter mass loss was the difference between spring mass in year $\mathrm{t}$ and autumn mass in year t-1 (Fig. 1). We obtained 1797 summer mass gain measures from 261 adult females and 157 adult males, and 1755 winter mass loss measures from 241 adult females and 153 adult males during 1973-2015. The number of measurements of summer mass gain or winter mass loss per adult ranged between 1-17 for females (averaging 5.44 and 5.75 measurements of summer and winter mass changes per ewe) and 1-7 for males (averaging 2.39 and 2.42 measurements of summer and winter mass changes per ram).

Weather and population density

Data on precipitation (rainfall plus water equivalent of snowfall in $\mathrm{mm}$ ) and average temperature $\left({ }^{\circ} \mathrm{C}\right)$ were obtained from the Environment Canada meteorological station at Nordegg, about 20 $\mathrm{km}$ west of Ram Mountain. Monthly temperature and precipitations were grouped as winter (December to March), spring (April and May), summer (June to September), and autumn (October and November) (Douhard et al. 2017). Most precipitation falls as snow in winter and autumn and as rain in summer. Spring precipitation is a mix of snow and rain. We therefore considered the effects of snowfall separately in spring only. Unfortunately, weather data were missing for some seasons (see Douhard et al. 2017 for details). We monitored daily temperature at Ram Mountain with iButtons (model DS1922L-F5\#) from 2011 to 2014. Correlations of daily temperatures for each month between Nordegg and Ram Mountain ranged from 0.40 to 0.97 with a mean of $r=0.82$ (Appendix S1).

We tested weather effects across these different seasons on winter mass loss, with weather conditions in summer and autumn measured in year t-1 and spring conditions in year $\mathrm{t}$ (Fig. 1).

This article is protected by copyright. All rights reserved 
We limited our analysis of summer mass gain to weather effects in current summer, previous spring and previous winter. Population density, the number of females aged 2 years and older in June (Jorgenson et al. 1998), varied markedly over the study (Douhard et al. 2017). We analysed the effects of population density in year t-1 on winter mass loss, and of density in year $t$ on summer mass gain.

\section{Statistical analyses}

All analyses were conducted in R version 3.1.2 (www.r-project.org) and mixed models were fitted using the lme4 package (Bates et al. 2015). Absolute mass changes are affected by mass at the beginning of each season (Pelletier et al. 2007b). Therefore, all analyses considered the effects of relative seasonal mass change, i.e. absolute mass change accounting for initial mass. We reported standardized regression coefficients (continuous predictor variables have mean $=0$ and standard deviation $=1$ ) to compare effect sizes.

Causes of seasonal mass changes. - Our analysis included two steps. We first tested and quantified the amount of temporal variation in seasonal mass changes accounted for by weather and population density using analysis of deviance (ANODEV, Grosbois et al. 2008). The ANODEV compares the deviance of the covariate model $\left(\mathrm{M}_{\mathrm{cov}}\right)$ to both the baseline $\left(\mathrm{M}_{\mathrm{cst}}\right)$ and the full time dependent $\left(\mathrm{M}_{\mathrm{t}}\right.$, including year as a factor) models as follows:

$$
\text { Fndf, ddf }=\frac{(\text { Dev Mcst }- \text { Dev Mcov }) /(n p \text { Mcov }- \text { np Mcst })}{(\text { Dev Mcov }- \text { Dev Mt }) /(n p \text { Mt }- \text { np Mcov })}
$$

where Dev and $n p$ are, respectively, the deviance and the number of parameters of models. This statistic follows a Fisher-Snedecor distribution, where the number of degrees of freedom for the numerator (ndf) is $n p M_{c o v}-n p M_{c s t}$ and the number of degrees of freedom for the denominator (ddf) is $n p M_{t}-n p M_{c o v}$. The ANODEV statistic is computed from individual-level data but it evaluates the impact of a covariate on annual variation in mass changes in the population. We considered the sexes separately because the baseline linear mixed model varied between males and females. For females, the baseline model included initial mass, as we considered relative mass changes, quadratic effects of age (Martin and Festa-Bianchet 2010) and reproductive status. In analyses of summer mass gain, female reproductive status was coded as a four-level factor: no lactation, lamb neonatal mortality, lamb summer mortality, and lamb survival to weaning (regardless of post-weaning survival). In analyses of winter mass loss, we considered the effects 
232 of female reproductive status in year t-1 (two levels: offspring weaned or not) and year t (three

233 levels: no lactation, lamb neonatal mortality, lamb neonatal survival). For summer mass gain and 234 winter mass loss of males, the baseline model included initial mass and a linear effect of age.

235 Sheep identity was included as a random factor. We checked for interactions between weather 236 and density, and as none was significant we describe only main effects. The $\mathrm{R}^{2}$ of the ANODEV 237 quantifies the temporal variation in average mass changes accounted for by each covariate as 238 follows:-

$$
\mathrm{R}^{2} \mathrm{ANODEV}=\frac{\text { Dev Mcov }- \text { Dev Mcst }}{\text { Dev Mt }- \text { Dev Mcst }}
$$

In a second step, we included all environmental covariates retained by ANODEV as fixed effects in the same linear mixed-model with individual identity and year as random factors, to obtain unbiased and robust parameter estimates. We calculated the total variance explained by

242 each final model of seasonal mass changes (fixed plus random effects) and the fixed effects alone using conditional and marginal $\mathrm{R}^{2}$ formulations, respectively (Nakagawa and Schielzeth 244 2013).

245 Reproductive consequences of seasonal mass changes. - Because of the timing of captures in our study, the reproductive consequences of winter mass loss in females can only be established by considering survival of lambs during summer and subsequent winter. A correlation between winter mass loss and probability of lactation or neonatal lamb survival would likely reflect the high energy costs of late gestation and early lactation. Our aim here was to determine the reproductive consequences and not the causes of maternal winter mass loss. We analysed the effects of maternal relative winter mass loss on lamb summer and winter survival using generalized linear mixed models (GLMMs) with a binomial distribution. In these analyses, relative winter mass loss was the residual of a regression between absolute winter mass loss and autumn mass in year t-1 (Appendix S2). Thus, individuals that lost more mass over winter than expected given their body mass the preceding autumn had the largest negative values. We also evaluated the impact of autumn mass in year $\mathrm{t}-1$, and its interaction with relative winter mass loss, on each female reproductive component. For lamb winter survival, we controlled for lamb sex (survival is lower for males than for females, Feder et al. 2008) and considered the potential influence of maternal relative summer gain and its interaction with previous winter mass loss. Summer mass gain was calculated as the residual of a regression between absolute summer gain 
and mass in spring (Appendix S2). We used linear mixed models to examine the effect of maternal relative winter mass loss on mass gain of lambs the subsequent summer while controlling for lamb sex and maternal summer mass gain. For adult males, we tested the effects of relative winter mass loss between year t-1 and t, summer mass gain and autumn mass in year $\mathrm{t}-1$ on the probability of siring a lamb in year $\mathrm{t}$ (Fig. 1) using GLMMs with a binomial distribution.

In all models of reproduction, we fitted year, individual identity and individual identity $\times$ seasonal mass change as random effects. The interaction between identity and seasonal mass change tests for individual differences in the effects of seasonal mass changes on reproduction. Individual identity and year were kept in the model independently of their significance. We selected the model with the lowest AIC and present AIC weight (wi, a measure of the likelihood that a given model is the best among the set of fitted models).

\section{RESULTS \\ Causes of seasonal mass changes}

Spring temperature was the most important variable affecting relative winter mass loss by females $\left(\mathrm{F}_{1,36}=30.41, \mathrm{P}<0.001, \mathrm{R}^{2}\right.$ ANODEV $\left.=46 \%\right)$. Cold springs increased winter mass loss (Fig. 2A). The ANODEV (Appendix S3) also indicated that relative winter mass loss by females was influenced by winter temperature $\left(\mathrm{F}_{1,36}=9.10, \mathrm{P}=0.004, \mathrm{R}^{2} \mathrm{ANODEV}=19 \%\right)$ and precipitation both in spring $\left(\mathrm{F}_{1,33}=3.98, \mathrm{P}=0.05, \mathrm{R}^{2}\right.$ ANODEV $\left.=11 \%\right)$ and winter $\left(\mathrm{F}_{1,32}=7.39, \mathrm{P}=\right.$ $0.01, \mathrm{R}^{2}$ ANODEV $\left.=19 \%\right)$. However, when we included all significant weather variables in the same model, only the effect of spring temperature remained statistically significant (Table 1), likely because of correlations among weather variables (Douhard et al. 2017). Our models control for variation in female age and reproductive status in year $\mathrm{t}-1$ and $\mathrm{t}$ (Table 1). Females that weaned a lamb the previous summer lost $3.8 \%$ less mass during winter than those that did not. Compared to non-lactating females, those whose lambs survived or did not survive the neonatal period in year $\mathrm{t}$ lost respectively $9.5 \%$ and $7.5 \%$ more mass. The final model explained $67 \%$ of the total variation in winter mass loss of females, of which $46 \%$ was explained by fixed effects (Table 1).

Similarly to what we found for females, cold springs led to greater relative winter mass loss of males $\left(F_{1,34}=4.84, P=0.03\right.$, Fig. $\left.2 B\right)$. Spring temperature accounted for $12 \%$ of annual 
variation in relative winter mass loss of males. Temperature and precipitation in winter seemed to play a role (Appendix S3), but again when we included all variables that were individually significant in the same model, only the effect of spring temperature tended to remain statistically significant (Table 1). There was no significant sex difference in the effects of spring temperature on relative winter mass loss (Wald test: difference of slope $=0.62, \mathrm{t}=0.98, \mathrm{P}=0.33$ ).

For both sexes, ANODEV analyses showed that spring temperature was the only environmental variable that influenced relative summer mass gain (females: $\mathrm{F}_{1,38}=5.49, \mathrm{P}=$ 0.02; males: $\mathrm{F}_{1,35}=6.70, \mathrm{P}=0.01$; see Appendix $\mathrm{S} 4$ for detailed results). It accounted for $13 \%$ and $16 \%$ of the annual variation in summer gain of females and males, respectively. Cold springs led to greater summer mass gain in both sexes (Table 2, Fig. 2C and 2D). We controlled for age in all models and for reproductive status for females. Females that weaned their lambs or lost their lambs during summer gained 14 and $12 \%$ less mass during summer than non-lactating females (Table 2).

Sheep that lost relatively more mass during winter gained relatively more mass in the subsequent summer (females: $\mathrm{r}=-0.33, \mathrm{P}<0.001$; males: $\mathrm{r}=-0.37, \mathrm{P}<0.001$ ). To test whether or not a simultaneous effect of spring temperature on summer mass gain and winter mass loss stems only from this correlation, we repeated the summer mass gain analyses after controlling for mass change the previous winter. The negative influence of spring temperature on summer gain remained in both sexes (females: $\beta=-0.73 \pm 0.35, \mathrm{P}=0.04$; males: $\beta=-1.09 \pm 0.47, \mathrm{P}=0.03$ ). Because it had opposite effects on winter loss and summer gain, spring temperature did not affect autumn mass of females $(\beta=0.07 \pm 0.30, \mathrm{P}=0.81)$ or males $(\beta=0.48 \pm 0.72, \mathrm{P}=0.51)$.

\section{Reproductive consequences of seasonal mass changes}

The best-supported model for lamb summer survival was the constant model (Table 3A). It received 1.4 and 2.4 times more support than the two closest models, which included maternal autumn mass or relative winter mass loss (Table 3A). These effects were weak and inconclusive (autumn mass: $\beta=0.14,95 \%$ CI [-0.09, 0.39]; winter mass loss: $\beta=-0.07,95 \%$ CI [-0.32, 0.19]). The best-supported model for lamb winter survival included only the effect of lamb sex (Table 3B). It received 1.9 times more support than the next closest model, which included relative winter mass loss of mothers (Table 3B). Although in the expected biological direction, the effect of previous maternal winter mass loss on lamb winter survival was not significant $(\beta=$ 
$0.10,95 \%$ CI $[-0.12,0.31])$. However, the summer mass gain of lambs was lower if their mothers had lost relatively more mass during the previous winter $(\beta=0.59,95 \% \mathrm{CI}[0.26,0.93]$, Fig. 3A) and lambs that gained more mass in summer were more likely to survive the winter $(\beta=0.14$, 95\% CI [0.06, 0.22], Fig. 3B). Maternal winter mass loss, therefore, appeared linked to increased lamb mortality the following winter through its effect on lamb summer mass gain.

For males, the probability of siring at least one lamb was best described by a model with only the positive influence of body mass in autumn before the rut (Appendix S5, $\beta=1.46,95 \%$ CI $[0.98,2.02])$. Neither relative summer mass gain before the rut $(\beta=0.009,95 \%$ CI $[-0.44$, $0.55])$ nor relative winter mass loss $(\beta=-0.02,95 \% \mathrm{CI}[-0.50,0.42])$ influenced male reproductive success.

Addition of an interaction between individual identity and relative seasonal mass change (winter mass loss or summer mass gain) as a random effect did not provide a better fit in any reproductive model for either sex.

Our study of bighorn sheep produced two major results: we identify spring temperature as the most important environmental variable affecting relative seasonal mass changes of both sexes and found that maternal relative winter mass loss was indirectly linked to increased lamb mortality the following winter, through its effect on lamb summer mass gain. For both sexes, spring temperature influenced relative winter mass loss and summer mass gain in opposite directions, resulting in no overall effect on autumn mass. Most studies of ungulates analyse body mass in a single season, typically autumn (Albon et al. 2017). Our findings suggest that such an approach may miss important but cryptic mechanisms behind the effects of climate change on demographic traits.

Previous studies examining the effects of environmental conditions on seasonal mass changes in mammals were restricted to juveniles (Cederlund et al. 1991, Loison et al. 1999a) or measured mass changes at the population level (Albon et al. 2017). Here, we reported strong effects of spring temperature on relative seasonal mass changes of adults using robust methods, such as the ANODEV (Grosbois et al. 2008). Our results are in line with other studies of large herbivores from northern latitudes and high altitudes, where individual performance depended strongly on spring weather through its influence on snow cover and plant phenology (Weladji et 
al. 2002, Pettorelli et al. 2005, Büntgen et al. 2014). Spring temperature accounted for $46 \%$ and $12 \%$ of the annual variation in winter mass loss of females and males, respectively. However, contrary to our prediction based on sex-specific reproductive constraints, the slope of the relationship between spring temperature and relative winter mass loss did not depend on sex, perhaps due to variation in reproductive behaviour within each sex. In both sexes, individuals that experienced cold springs lost relatively more mass over winter but gained more mass during summer. Summer mass gain depends, to a certain extent, on previous winter mass loss (FestaBianchet et al. 1996, Pelletier et al. 2007b), but the negative influence of spring temperature on relative summer gain remained after controlling for relative mass change the previous winter. Warmer springs generally lead to earlier and faster snowmelt, favoring an earlier start of vegetation growth (Myneni et al. 1997) which may advance the restoration of mass and therefore reduce overwinter mass loss. Bighorn sheep at Ram Mountain may start gaining mass in May (Festa-Bianchet et al. 1996). Warm temperatures in spring also favor rapid vegetation growth (Pettorelli et al. 2007). There is, however, a trade-off between plant productivity and duration of the period of access to high-quality forage (Van der Wal 2000, Seydack et al. 2012). Warm temperature in spring may also reduce spatial heterogeneity in timing of green-up if it generates rapid snowmelt over the landscape, decreasing the period of access to high-quality forage (Mysterud et al. 2001, Pettorelli et al. 2007). These different mechanisms may account for the negative influence of warm spring temperature on relative summer mass gain. Although snow cover likely is an important pathway through which spring temperature influences seasonal mass changes of bighorn sheep, we found no effect of snowfalls in winter and spring. While temperature at the weather station correlates well with that of the study area, snow data may be less representative. Because the weather station lies at lower altitude $(1332 \mathrm{~m})$ than the study area (1700- $2170 \mathrm{~m})$, the proportion of spring precipitation falling as snow at Ram Mountain is inevitably higher than at the weather station.

In our models of seasonal mass changes in females, we controlled for costs of reproduction. We measured winter mass loss from mid-September to early June. On average, $70 \%$ of lambs are born before June $5^{\text {th }}$ at Ram Mountain (Feder et al. 2008). Energy requirements for female mammals are particularly high during the first month of lactation, and for ungulates $>90 \%$ of the energy cost of gestation occurs during the last trimester (Parker et al. 2009). Capital breeder species, such as bighorn sheep (Festa-Bianchet et al. 1998) and caribou 
(Barboza and Parker 2008), rely heavily on body reserves to meet the energetic costs of reproduction. For example, female caribou lose mass for about 3 weeks following calving (Parker et al. 1990). The high energy costs of late gestation and early lactation may explain why lactating females lost relatively more mass overwinter than non-lactating females. Seasonal mass gain probably begins in May at Ram Mountain (Festa-Bianchet et al. 1996), but females that allocate more resources to reproduction may gain less mass at this time. Supporting this view, females that lactated during summer gained 12-14\% less mass than non-lactating females between June and September.

The reproductive consequences of female winter mass loss only became measurable in our study when considering females whose lambs survived the neonatal period. Relative maternal winter mass loss had a negative effect on lamb summer mass gain, which in turn, influence lamb mortality the following winter. Lambs must gain enough mass during summer to survive the winter (Martin and Festa-Bianchet 2010). We suggest that mothers that lost relatively more mass in winter allocated less to reproduction and more to rebuilding their own body reserves over the following summer (Festa-Bianchet and Jorgenson 1998). Our results are in line with findings showing that female large herbivores generally adopt a conservative reproductive tactic (Gaillard and Yoccoz 2003).

Summer and winter survival of lambs did not vary with maternal mass in the previous autumn. However, heavier females in autumn had a higher probability of lactation the following year (GLMM, $\beta=1.25,95 \%$ CI $[0.84,1.71])$ and their lambs were more likely to survive the neonatal period(GLMM, $\beta=0.32,95 \%$ CI $[0.15,0.48])$. The positive influence of maternal mass on neonatal survival may be mediated by birth mass. A recent meta-analysis showed that maternal mass provides a reliable predictor of offspring birth mass in mammals (Ronget et al. in press). This meta-analysis also found a strong support for an overall positive effect of offspring body mass on offspring survival, especially in wild mammal populations with no predation (Ronget et al. in press). In species with relatively long lactation periods, however, post-partum maternal care likely plays a greater role than birth mass in the future survival of offspring (Maniscalco et al. 2014).

In sexually dimorphic mammals, body mass is an important determinant of male reproductive success (Galimberti et al. 2007 in southern elephant seal Mirounga leonina, 
412 Mainguy et al. 2009 in mountain goats Oreamnos americanus, Coltman et al. 2002 and this study

413 in bighorn sheep). The effects of seasonal mass changes on male reproduction, however, have

414 received little attention. For male large herbivores, the highest energy expenditures occur during

415 the rut (Parker et al. 2009), coinciding with a reduction in food intake (Bobek et al. 1990,

416 Miquelle 1990, Pelletier 2005). A few studies used relative mass loss during the rut to estimate

417 male reproductive effort (Yoccoz et al. 2002, Mysterud et al. 2005), but there is no evidence that

418 mass loss during the rut predicts paternity in male ungulates. Mass loss during the rut was

419 uncorrelated with mating success in male fallow deer (Dama dama) (McElligott et al. 2003). In

420 bighorn males, relative mass loss during winter did not influence the probability of having at

421 least one lamb the following spring. The rut begins in mid-November and lasts for about 3 weeks

422 (Pelletier 2005). We measured winter mass loss over a much longer period and cannot estimate

423 mass changes between the rut and early June. If relative mass loss during winter is a reliable

424 index of mating effort, our results suggest that greater mating effort did not necessarily translate

425 into greater reproductive success.

Ecological responses to climate can vary between species that are phylogenetically or ecologically similar (Tafani et al. 2013) and even between populations of the same species (Loison et al. 1999b, Martínez-Jauregui et al. 2009). Our study suggests that contrasting patterns can also emerge when considering seasonal mass changes within a population. Climate change is expected to have major impacts on species living in extreme environments (Parmesan 2006). Furthermore, species with restricted habitat requirements, such as bighorn sheep, are expected to 432 be particularity sensitive to the effects of climate change. At Ram Mountain, mean winter and summer temperatures have increased by $2-3^{\circ} \mathrm{C}$ over the last few decades (Douhard et al. 2017). There is as yet no temporal trend in spring temperature, but mean temperatures for all seasons are expected to increase in Canada (Bush et al. 2014). At Ram Mountain, winter lamb survival increased with spring temperature in the year of birth (Portier et al. 1998). Juvenile survival, 437 despite a low relative impact on population growth rate compared with adult survival, is critical 438 in population dynamics of large herbivores because of its high temporal variation (Gaillard et al. 439 2000). Juvenile winter survival is often (but not always, Eacker et al. 2017) one of the principal demographic parameters determining population growth of large mammals, including bighorn sheep (Coulson et al. 1999, Coulson et al. 2005). Here, we reveal a mechanism that may lead to a 442 positive impact of climate change on population dynamics of this alpine ungulate. More 
generally, our results suggest that seasonal mass changes considerations can detect cryptic mechanisms of how climate change influences demographic traits.

\section{ACKNOWLEDGMENTS}

Animal-handling procedures were approved by the Animal Care Committee of the University of Sherbrooke (protocols MFB2009-01 and FP2012-01), affiliated to the Canadian Council on Animal Care. This work was funded by a Natural Sciences and Engineering Research Council of Canada CREATE EnviroNord post-doctoral fellowship to M. Douhard. M. Festa-Bianchet and F. Pelletier are funded by NSERC Discovery Grants and by research grants from the Alberta Conservation Association. F. Pelletier holds the Canada Research Chair in Evolutionary Demography and Conservation. We thank A. Hubbs, C. Feder, J. Hogg and J. Jorgenson for their support of the Ram Mountain research program, and all assistants and students who worked on Ram Mountain over decades. D. Coltman generously provided data on paternities. We thank Mark Hebblewhite and two anonymous referees for insightful comments which greatly improved the manuscript.

\section{LITERATURE CITED}

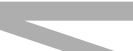

Albon, S. D., et al. 2017. Contrasting effects of summer and winter warming on body mass explain population dynamics in a food-limited Arctic herbivore. Global Change Biology 23:1374-1389.

Altwegg, R., and M. D. Anderson. 2009. Rainfall in arid zones: possible effects of climate change on the population ecology of blue cranes. Functional Ecology 23:1014-1021. Anderson, R. P. 2013. A framework for using niche models to estimate impacts of climate change on species distributions. Annals of the New York Academy of Sciences 1297:8-28. Barboza, P. S., and K. L. Parker. 2008. Allocating protein to reproduction in arctic reindeer and caribou. Physiological and Biochemical Zoology 81:835-855.

Bates, D., M. Maechler, B. Bolker, and S. Walker. 2015. Fitting linear mixed-effects models using lme4. Journal of Statistic Software 67:1-48.

Bobek, B., K. Perzanowski, and J. Weiner. 1990. Energy expenditure for reproduction in male red deer. Journal of Mammalogy 71:230-232.

Bonenfant, C., et al. 2009. Empirical evidence of density-dependence in populations of large herbivores. Advances in Ecological Research 41:313-357. 
473 Büntgen, U., A. Liebhold, H. Jenny, A. Mysterud, S. Egli, D. Nievergelt, N. C. Stenseth, and K. 474 Bollmann. 2014. European springtime temperature synchronises ibex horn growth across the eastern Swiss Alps. Ecology letters 17:303-313.

Bush, E. J., J. W, Loder, T. S. James, L. D. Mortsch, and S. J. Cohen. 2014. An overview of Canada's changing climate. Canada in a changing climate: sector perspectives on impacts and adaptation, (eds F. J. Warren and D. S. Lemmen), pp. 23-64. Government of Canada, Ottawa. Calder, W. A. 1984. Size, function and life history. Harvard University Press, Cambridge, USA. Cederlund, G. N., H. K. G. Sand, and A. Pehrson. 1991. Body mass dynamics of moose calves in relation to winter severity. The Journal of Wildlife Management 55:675-681.

Clutton-Brock, T. H., I. R. Stevenson, P. Marrow, A. D. C. MacColl, A. I. Houston, and J. M. McNamara. 1996. Population fluctuations, reproductive costs and life history tactics in female Soay sheep. Journal of Animal Ecology 65: 675-689.

Coltman, D. W., M. Festa-Bianchet, J. T. Jorgenson, and C. Strobeck. 2002. Age-dependent sexual selection in bighorn rams. Proceedings of the Royal Society of London B 269:165-172. Cook, R. C., J. G. Cook, D. L. Murray, P. Zager, B. K. Johnson, and M. W. Gratson. 2001. The Journal of Wildlife Management 65:973-987.

Coulson, T., S. Albon, J. Pilkington, and T. Clutton-Brock. 1999. Small-scale spatial dynamics in a fluctuating ungulate population. Journal of Animal Ecology 68:658-671.

Coulson, T., J.-M. Gaillard, M. Festa-Bianchet. 2005. Decomposing the variation in population growth into contributions from multiple demographic rates. Journal of Animal Ecology 74:789_ 801.

Dobson, F. S. 1992. Body mass, structural size, and life-history patterns of the Columbian ground squirrel. American Naturalist 140:109-125.

Douhard, M., G. Pigeon, M. Festa-Bianchet, D. W. Coltman, S. Guillemette, and F. Pelletier. 2017. Environmental and evolutionary effects on horn growth of male bighorn sheep. Oikos 126: 1031-1041. Eacker, D. R., P. M. Lukacs, K. M. Proffitt, and M. Hebblewhite. 2017. Assessing the importance of demographic parameters for population dynamics using Bayesian integrated population modeling. Ecological Applications 27:1280-1293. 
Feder, C., J. G. A. Martin, M. Festa-Bianchet, C. Bérubé, and J. T. Jorgenson. 2008. Never too late? Consequences of late birthdate for mass and survival of bighorn lambs. Oecologia 156:773781.

Festa-Bianchet, M., J. T. Jorgenson, W. J. King, K. G. Smith, and W. D. Wishart. 1996. The development of sexual dimorphism: seasonal and lifetime mass changes in bighorn sheep. Canadian Journal of Zoology 74:330-342.

Festa-Bianchet, M. 1998. Condition-dependent reproductive success in bighorn ewes. Ecology Letters 1:91-94.

Festa-Bianchet, M., J.-M. Gaillard, and J. T. Jorgenson. 1998. Mass- and density-dependent reproductive success and reproductive costs in a capital breeder. American Naturalist 152:367379.

Festa-Bianchet, M., and J. T. Jorgenson. 1998. Selfish mothers: reproductive expenditure and resource availability in bighorn ewes. Behavioral Ecology 9:144-150.

Festa-Bianchet, M. 2012. The cost of trying: weak interspecific correlations among life-history components in male ungulates. Canadian Journal of Zoology 90:1072-1085.

Gaillard, J.-M., M. Festa-Bianchet, N. G. Yoccoz, A. Loison, and C. Toïgo. 2000. Temporal variation in fitness components and population dynamics of large herbivores. Annual Review of Ecology and Systematics 31:367-393.

Gaillard, J.-M., and N. G. Yoccoz. 2003. Temporal variation in survival of mammals: a case of environmental canalization? Ecology 84:3294-3306.

Galimberti, F., S. Sanvito, C. Braschi, and L. Boitani. 2007. The cost of success: reproductive effort in male southern elephant seals (Mirounga leonina). Behaviour Ecology and Sociology 62:159-171.

Griffin, K. A., et al. 2011. Neonatal mortality of elk driven by climate, predator phenology and predator community composition. Journal of Animal Ecology 80:1246-1247.

Grosbois, V., O. Gimenez, J.-M. Gaillard, R. Pradel, C. Barbraud, J. Clobert, A. P. Møller, and H. Weimerskirch. 2008. Assessing the impact of climate variation on survival in vertebrate populations. Biological Reviews 83:357-399.

Hansen, B. B., V. Grøtan, R. Aanes, B. E. Sæther, A. Stien, E. Fuglei, R. A. Ims, N. G. Yoccoz, and A. Ø. Pedersen. 2013. Climate events synchronize the dynamics of a resident vertebrate community in the high Arctic. Science 339:313-315. 
Hansen, B. B., K. Isaksen, R. E. Benestad, J. Kohler, A. Ø. Pedersen, L. E. Loe, S. J. Coulson, J. O. Larsen, and $\varnothing$ Varpe. 2014. Warmer and wetter winters: characteristics and implications of an extreme weather event in the high Arctic. Environmental Research Letters 9:114021. IPCC. 2014. Fifth assessment report of the intergovernmental panel on climate change. IPCC, Geneva, Switzerland.

Jorgenson, J. T., M. Festa-Bianchet, and W. D. Wishart. 1993. Harvesting bighorn ewes: consequences for population size and trophy ram production. The Journal of wildlife management 57:429-435.

Jorgenson, J. T., M. Festa-Bianchet, J.-M. Gaillard and W. D. Wishart. 1997. Effects of age, sex, disease and density on survival of bighorn sheep. Ecology 78:1019-1032.

Jorgenson, J.T., M. Festa-Bianchet, and W. D. Wishart 1998. Effects of population density on horn development in bighorn rams. The Journal of Wildlife Management 62:1011-1020. Loison, A., R. Langvatn, and E. J. Solberg. 1999a. Body mass and winter mortality in red deer calves: disentangling sex and climate effects. Ecography 22:20-30.

Loison, A., J.-M.Julien, and P. Menaut. 1999b. Relationship between chamois and isard survival and variation in global and local climate regimes: contrasting examples from the Alps and Pyrenees. Ecological Bulletins 47:126-136.

Mainguy, J., S. D. Côté, M. Festa-Bianchet, and D. W. Coltman. 2009. Father-offspring phenotypic correlations suggest intralocus sexual conflict for a fitness-linked trait in a wild sexually dimorphic mammal. Proceedings of the Royal Society of London B 276:4067-4075. Maniscalco, J. M. 2014. The effects of birth weight and maternal care on survival of juvenile Steller sea lions (Eumetopias jubatus). PLos ONE 9: e96328.

Martin, J. G. A., and M. Festa-Bianchet. 2010. Bighorn ewes transfer the costs of reproduction to their lambs. American Naturalist 176:414-423.

Martin, J. G. A., and F. Pelletier. 2011. Measuring growth patterns in the field: effects of sampling regime and methods on standardized estimates. Canadian Journal of Zoology 89:529_ 537.

Martin, J. G. A., and M. Festa-Bianchet. 2012. Determinants and consequences of age of primiparity in bighorn sheep, Ovis canadensis. Oikos 121:752-760.

Martínez-Jauregui, M., A. San Miguel-Ayanz, A. Mysterud, C. Rodríguze-Vigal, T. CluttonBrock, R. Langvatn, and T. Coulson. 2009. Are local weather, NDVI and NAO consistent 
564 determinants of red deer weight across three contrasting European countries? Global Change 565 Biology 15:1727-1738.

566 McCullough, D. R. 1999. Density dependence and life-history strategies of ungulates. Journal of 567 Mammalogy 80:1130-1146.

568 McElligott, A. G., F. Naulty, W. V. Clarke, and T. J. Hayden. 2003. The somatic cost of 569 reproduction: what determines reproductive effort in prime-aged fallow bucks? Evolutionary 570 Ecology Research 5:1239-1250.

571 Milner, J. M., A. Stien, R. J. Irvine, S. D. Albon, R. Langvatn, and E. Ropstad. 2003. Body

572 condition in Svalbard reindeer and the use of blood parameters as indicators of condition and 573 fitness. Canadian Journal of Zoology 81:1566-1578.

574 Milner, J. M., F. M. van Beest, E. J. Solberg, and T. Storaas. 2013. Reproductive success and 575 failure: the role of winter body mass in reproductive allocation in Norwegian moose. Oecologia 576 172:995-1005.

577 Miquelle, D. G. 1990. Why don’t bull moose eat during the rut? Behaviour Ecology and

578 Sociology 27:145-151.

579 Monteith, K. L., T. R. Stephenson, V. C. Bleich, M. M. Conner, B. M. Pierce, and R. T. Bowyer.

580 2013. Risk-sensitive allocation in seasonal dynamics of fat and protein reserves in a long-lived 581 mammal. Journal of Animal Ecology 82:377-388.

582 Myneni, R. B., C. D. Keeling, C. J. Tucker, G. Asrar, and R. R. Nemani. 1997. Increased plant 583 growth in the northern high latitudes from 1981 to 1991. Nature 386:698-702.

584 Mysterud, A., N. C. Stenseth, N. G. Yoccoz, R. Langvatn and G. Steinheim. 2001. Nonlinear 585 effects of large-scale climatic variability on wild and domestic herbivores. Nature 410:10965861099.

587 Mysterud, A., R. Langvatn, and N. C. Stenseth. 2004. Patterns of reproductive effort in male 588 ungulates. Journal of Zoology, London 264:209-215.

589 Mysterud, A., E. J. Solberg, and N. G. Yoccoz. 2005. Ageing and reproductive effort in male 590 moose under variable levels of intrasexual competition. Journal of Animal Ecology 74:742-754. 591 Nakagawa, S., and H. Schielzeth. 2013. A general and simple method for obtaining $\mathrm{R}^{2}$ from 592 generalized linear mixed-effects models. Methods in Ecology and Evolution 4:133-142. 
NOAA National Centers for Environmental Information. 2017. State of the climate: global analysis for annual 2016. Published online January 2017 at https://www.ncdc.noaa.gov/sotc/global/201.

$$
\text { Parker, K. L., R. G. White, M. P. Gillingham, D. F. Holleman. 1990. Comparison of energy }
$$
metabolism in relation to daily activity and milk consumption by caribou and muskox neonates. Canadian Journal of Zoology 68:106-114.

Parker, K. L., P. S. Barboza, and M. P. Gillingham. 2009. Nutrition integrates environmental responses of ungulates. Functional Ecology 23:57-69.

Parmesan, C. 2006. Ecological and evolutionary responses to recent climate change. Annual Review of Ecology and Systematics 37:637-669.

Pelletier, F. 2005. Foraging time of rutting bighorn rams varies with individual behavior, not mating tactic. Behavioral Ecology 16:280-285.

Pelletier, F., T. H. Clutton-Brock, J. M. Pemberton, S. Tuljapurkar, and T. N. Coulson. 2007a.

The evolutionary demography of ecological change: linking trait variation and population growth. Science 315:1571-1574.

Pelletier, F., D. Réale, D. Garant, D.W. Coltman, and M. Festa-Bianchet. 2007b. Selection on heritable seasonal phenotypic plasticity of body mass. Evolution 61:1969-1979.

Peters, R. H. 1983. The ecological implications of body size. Cambridge University Press, NewYork, USA.

Pettorelli, N., A. Mysterud, N. G. Yoccoz, R. Langvatn, and N. C. Stenseth. 2005. Importance of climatological downscaling and plant phenology for red deer in heterogeneous landscapes.

Proceedings of the Royal Society of London B 272: 2357-2364.

Pettorelli, N., F. Pelletier, A. V. Hardenberg, M. Festa-Bianchet, and S. D. Côté. 2007. Early onset of vegetation growth vs. rapid green-up: Impacts on juvenile mountain ungulates. Ecology 88:381-390.

Portier, C., M. Festa-Bianchet, J.-M. Gaillard, J. T. Jorgenson and N. G. Yoccoz. 1998. Effects of density and weather on survival of bighorn sheep lambs (Ovis canadensis). Journal of Zoology, London 245:271-278.

Rebke, M., T. Coulson, P. H. Becker, J. W. Vaupel. 2010. Reproductive improvement and senescence in a long-lived bird. Proceedings of the National Academy of Sciences of the USA 107: 7841-7846.

This article is protected by copyright. All rights reserved 
624 Ronget, V., J.-M. Gaillard, T. Coulson, M. Garratt, F. Gueyffier, J.-C. Lega, J.-F. Lemaître. In

625

626

627

628

629

630

631

632

633

634

635

636

637

638

639

640

641

642

643

644

645

646

647

648

649

650

651

652

653

press. Causes and consequences of variation in offspring body mass: meta-analyses in birds and mammals. Biological Reviews.

Root, T. L., and L. Hughes. 2005. Present and future phenological changes in wild plants and animals. Pages 61-74 in T. E. Lovejoy, L. Hannah, editors. Climate change and biodiversity. Teri Press, New Dehli, India.

Selwood, K. E., M. A. McGeoch, and R. Mac Nally. 2015. The effects of climate change and land-use change on demographic rates and population viability. Biological Reviews 90:837-853.

Seydack, A. H., I. P. Smit, W. J. Vemeulen, J. Baard, and N. Zambatis. 2012. Climate and vegetation in a semi-arid savanna: development of a climate-vegetation response model linking plant metabolic performance to climate and the effects on forage availability for large herbivores. Koedoe 54:1-12.

Stearns, S. C. 1992. The evolution of life histories. Oxford University Press, New York, USA. Stephens, P. A., I. L. Boyd, J. M. McNamara, and A. I. Houston. 2009. Capital breeding and income breeding: their meaning, measurement, and worth. Ecology 90:2057-2067.

Tafani, M., A. Cohas, C. Bonenfant, J.-M. Gaillard, and D. Allainé. 2013. Decreasing litter size of marmots over time: a life history response to climate change? Ecology 94:580-586.

Toïgo, C., J.-M. Gaillard, G. Van Laere, A. J. M. Hewison, and N. Morellet. 2006. How does environmental variation influence body mass, body size, and body condition? Roe deer as a case study. Ecography 29: 301-308.

Van Beest, F. M., and J. M. Milner. 2013. Behavioural responses to thermal conditions affect seasonal mass change in a heat-sensitive northern ungulate. PLoS ONE 8:e65972.

Van der Wal, R., N. Madan, S. van Lieshout, C. Dormann, R. Langvatn, and S. D. Albon. 2000. Trading forage quality for quantity? Plant phenology and patch choice by Svalbard reindeer. Oecologia 123:108-115.

Walther, G.-R., E. Post, P. Convey, A. Menzel, C. Parmesan, T. J. C. Beebee, J.-M. Fromentin, O. Hoegh-Guldberg, and F. Bairlein. 2002. Ecological responses to recent climate change. Nature 416:389-395.

Weladji, R. B., D. R. Klein, Ø. Holand, and A. Mysterud. 2002. Comparative response of Rangifer tarandus and other northern ungulates to climatic variability. Rangifer 22:33-50. 
654 Yoccoz, N. G., A. Mysterud, R. Langvatn, and N. C. Stenseth. 2002. Age- and density-dependent 655 reproductive effort in male red deer. Proceedings of the Royal Society of London B 269:15236561528.

\section{Tables}

658

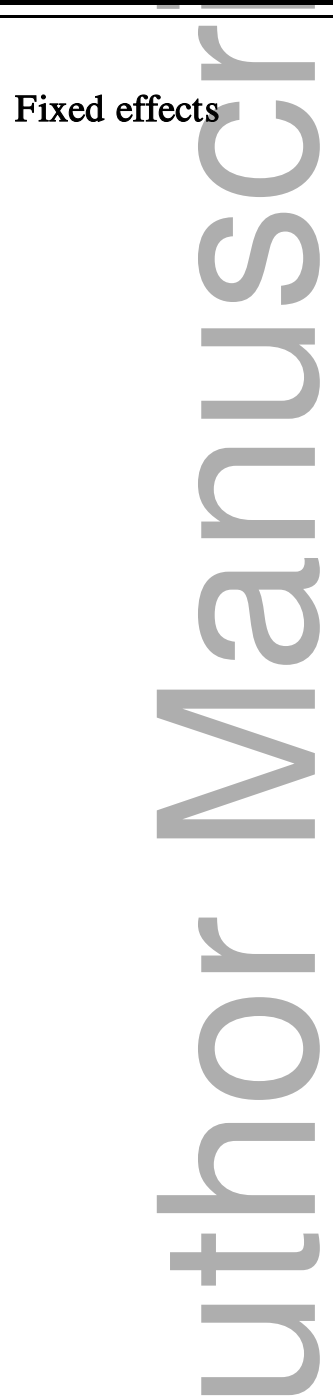

659 Table 1. Final linear mixed models of winter mass loss for female and male bighorn sheep at 660 Ram Mountain, Alberta, Canada. 


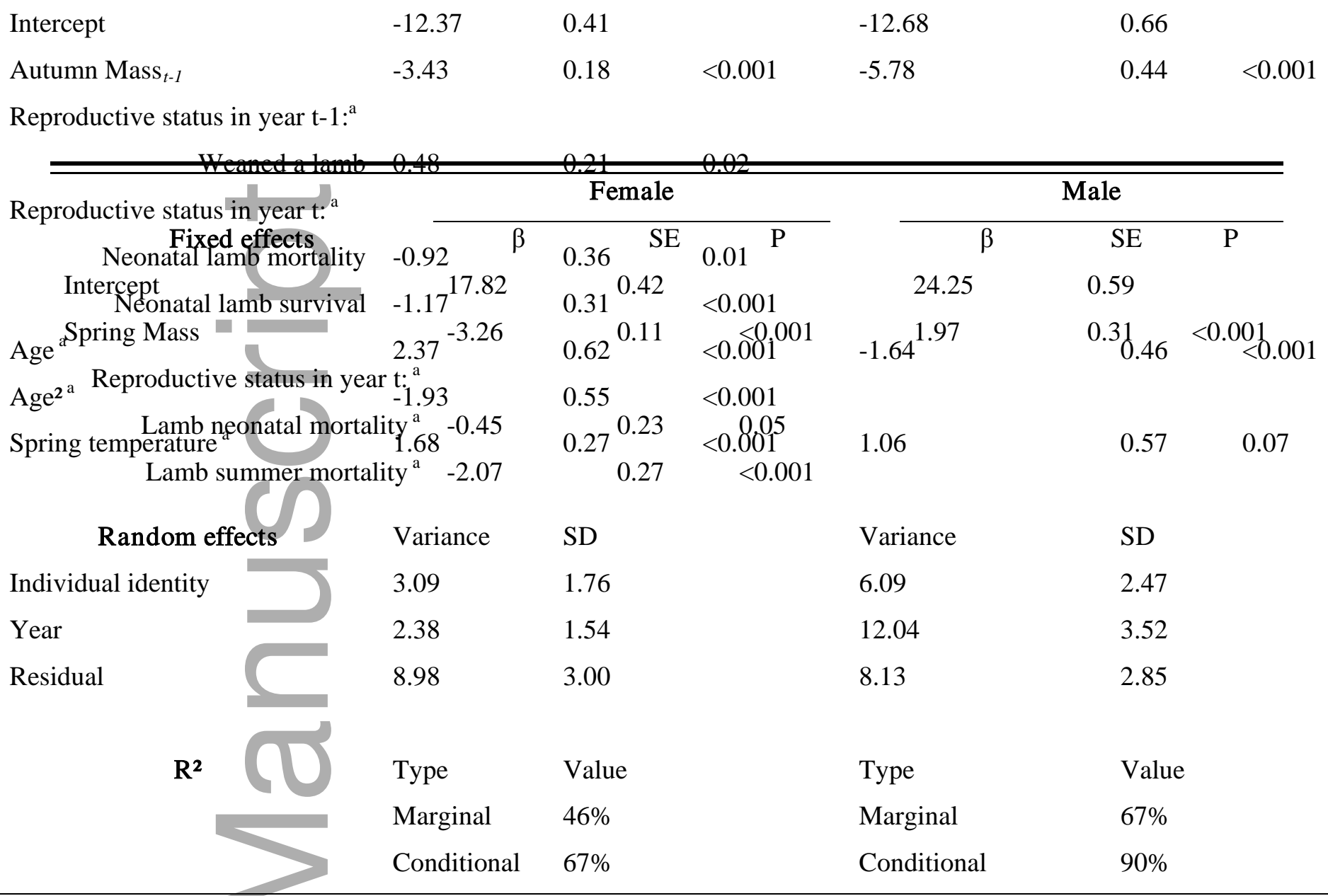

661 Note: winter mass loss was measured between year t-1 and t, autumn mass in year t-1 (see Fig.1).

662 Females with no lamb weaned and those with no evidence of lactation were considered as references in

663 the reproductive status in year $\mathrm{t}-1$ and in year $\mathrm{t}$, respectively. Variables dropped from the final models

664 were: spring precipitation $(\beta=-0.30 \pm 0.27, \mathrm{P}=0.28$ for females), winter precipitation $(\beta=-0.06 \pm 0.36$,

$665 \mathrm{P}=0.87$ for females, $\beta=-0.28 \pm 0.65, \mathrm{P}=0.67$ for males $)$ and winter temperature $(\beta=0.35 \pm 0.34, \mathrm{P}=$

6660.31 for females, $\beta=0.83 \pm 0.59, \mathrm{P}=0.18$ for males).

$667{ }^{a}$ Because models included autumn mass, these are effects on relative winter mass loss. 


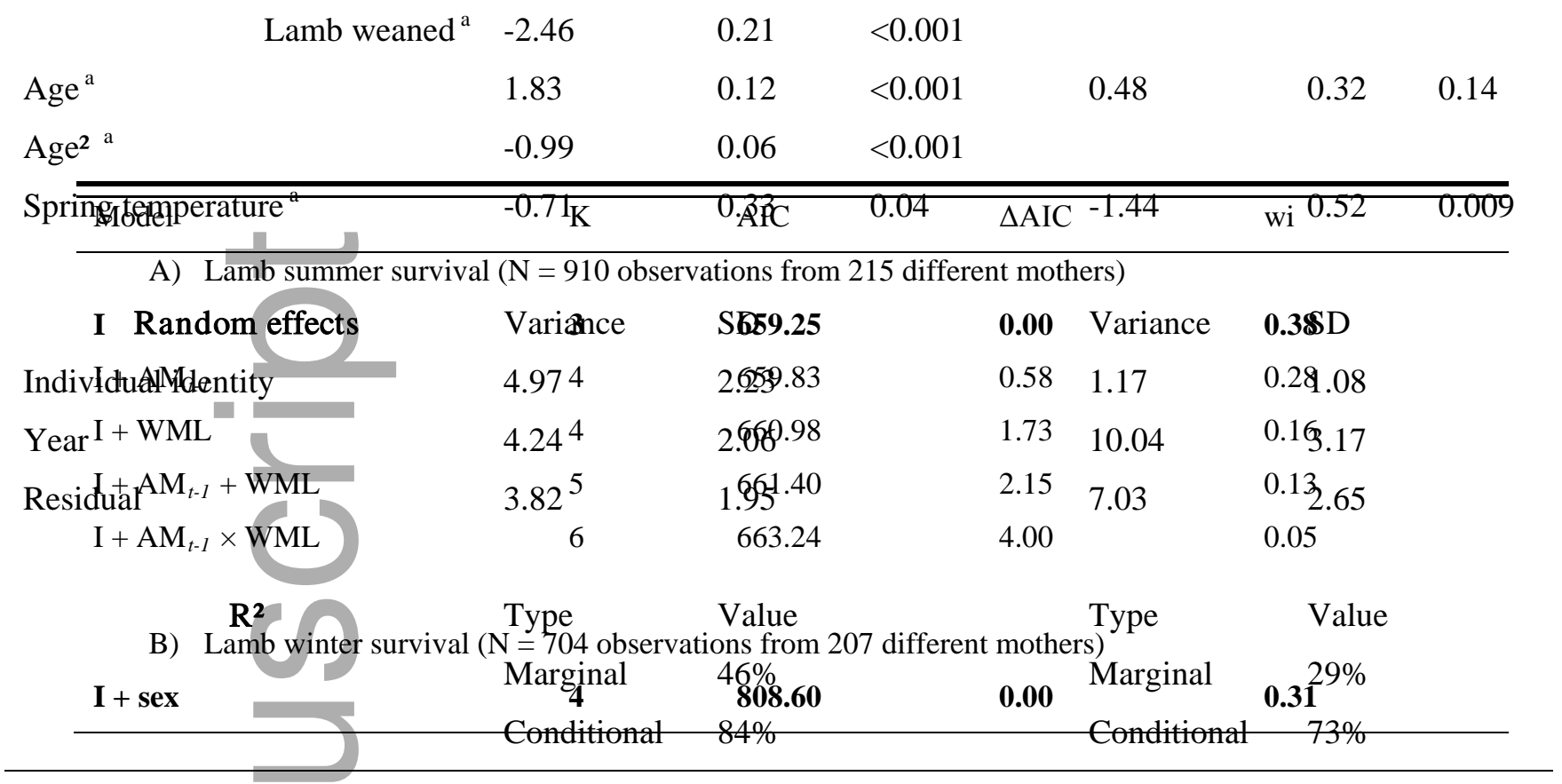

668 Table 2. Final linear mixed models of summer mass gain for female and male bighorn sheep at 669 Ram Mountain, Alberta, Canada.

670 Note: Non-lactating female was the reference in the reproductive status in year $\mathrm{t}$.

$671{ }^{a}$ Because models included spring mass, these are effects on relative summer mass gain.

672

673 Table 3. Model selection results for summer and winter survival of bighorn sheep lambs at Ram 674 Mountain, Alberta, Canada. 


\begin{tabular}{lllll}
\hline I + sex + WML & 5 & 809.86 & 1.26 & 0.16 \\
I + sex + $\mathrm{AM}_{t}$ & 5 & 810.28 & 1.68 & 0.13 \\
I + sex + SMG & 5 & 810.30 & 1.69 & 0.13 \\
I + sex + AM t- $_{\text {I }}$ & 5 & 810.55 & 1.94 & 0.12 \\
I + sex + WML $\times$ SMG & 6 & 811.15 & 2.55 & 0.09 \\
I + sex + WML $\times$ AM $_{t-1}$ & 7 & 813.14 & 4.54 & 0.03 \\
\hline
\end{tabular}

675 Note: Summer survival indicates whether the lamb seen in June did (score $=1)$ or did not (score $=0$ ) 676 survive to mid-September (the approximate time of weaning). Winter survival indicates whether the lamb 677 seen in mid-September did $($ score $=1$ ) or did not (score $=0$ ) survive to 1 year of age. Maternal autumn 678 mass was measured in year $\mathrm{t}-1\left(\mathrm{AM}_{\mathrm{t}-1}\right)$ and year $\mathrm{t}\left(\mathrm{AM}_{\mathrm{t}}\right)$. Maternal winter mass loss (WML) was 679 measured between year $\mathrm{t}-1$ and $\mathrm{t}$ and summer mass gain (SMG) in year $\mathrm{t}$ (see Fig.1). Autumn mass is an 680 absolute measure while seasonal mass changes are relative (Appendix S2). The base model for lamb winter survival contains the effect of lamb sex (see Material and methods). Year and female identity were included in all models as random effects. $\mathrm{K}$ indicates the number of estimated parameters in each model, $\triangle \mathrm{AIC}$ is the AIC difference between each candidate model and the best-supported model for each analysis, and wi correspond to Akaike weights. Selected models are shown in bold. $\mathrm{I}=$ intercept, $\times=$ interaction.

Figure legends

687

Fig. 1. The bighorn sheep year showing when variables under consideration were measured.

Fig. 2. Effects of average spring temperature on relative winter body mass loss of A) female and B) male and on relative summer mass gain of C) female and D) male adult bighorn sheep at Ram Mountain. The $y$-axis shows averages \pm SE of residuals from a linear mixed model of absolute 692 seasonal mass change controlling for initial mass (Appendix S2), age, and reproduction for 693 females (see Tables 1 and 2). Individuals that lose relatively more mass during winter have the 694 largest negative values, those that gain relatively more mass during summer have the largest 695 positive values. Lines show linear regressions models between spring temperature and y 696 variables.

697 Fig. 3. A) Effects of maternal relative winter mass loss on lamb summer mass gain at Ram 698 Mountain (408 observations of 164 females). Points represent residual lamb summer mass gain 
699 after accounting for the effect of lamb sex and maternal summer mass gain. Females that lose 700 more mass than expected for their body mass the preceding autumn have the largest negative 701 values. B) Winter survival according to summer mass gain and sex for lambs (393 observations 702 of 164 females). Mother identity and year of lamb birth were fitted as random effects. Lines 703 represent the model predictions.

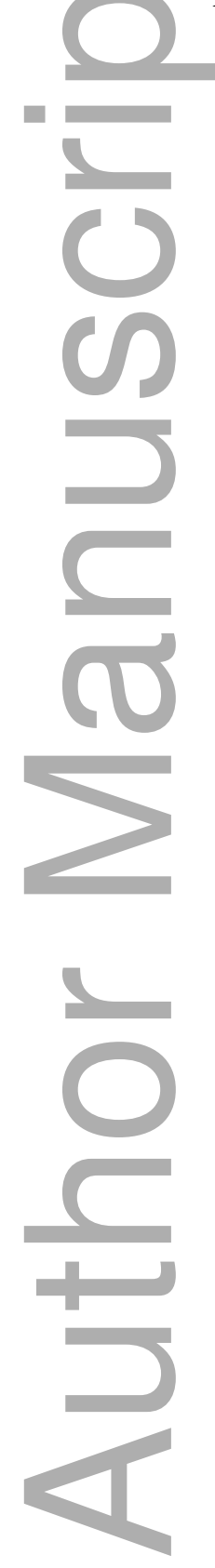




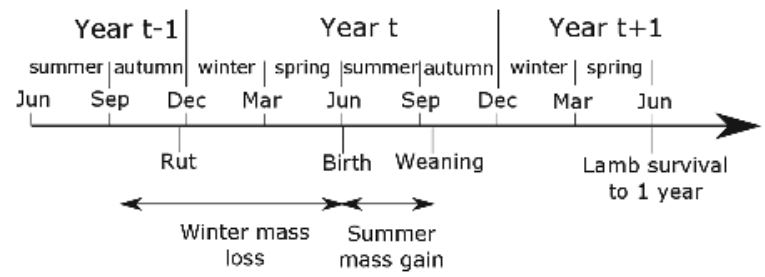

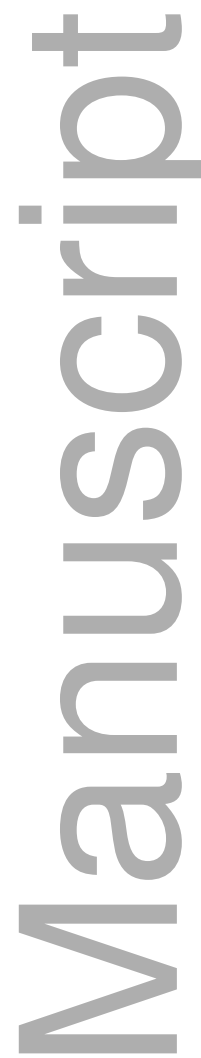

ecy_2141_f1.tif

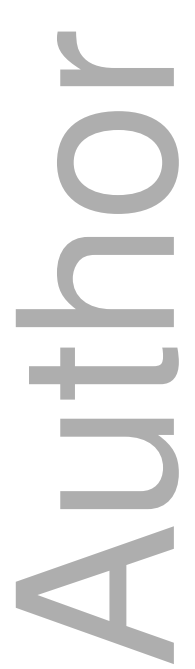



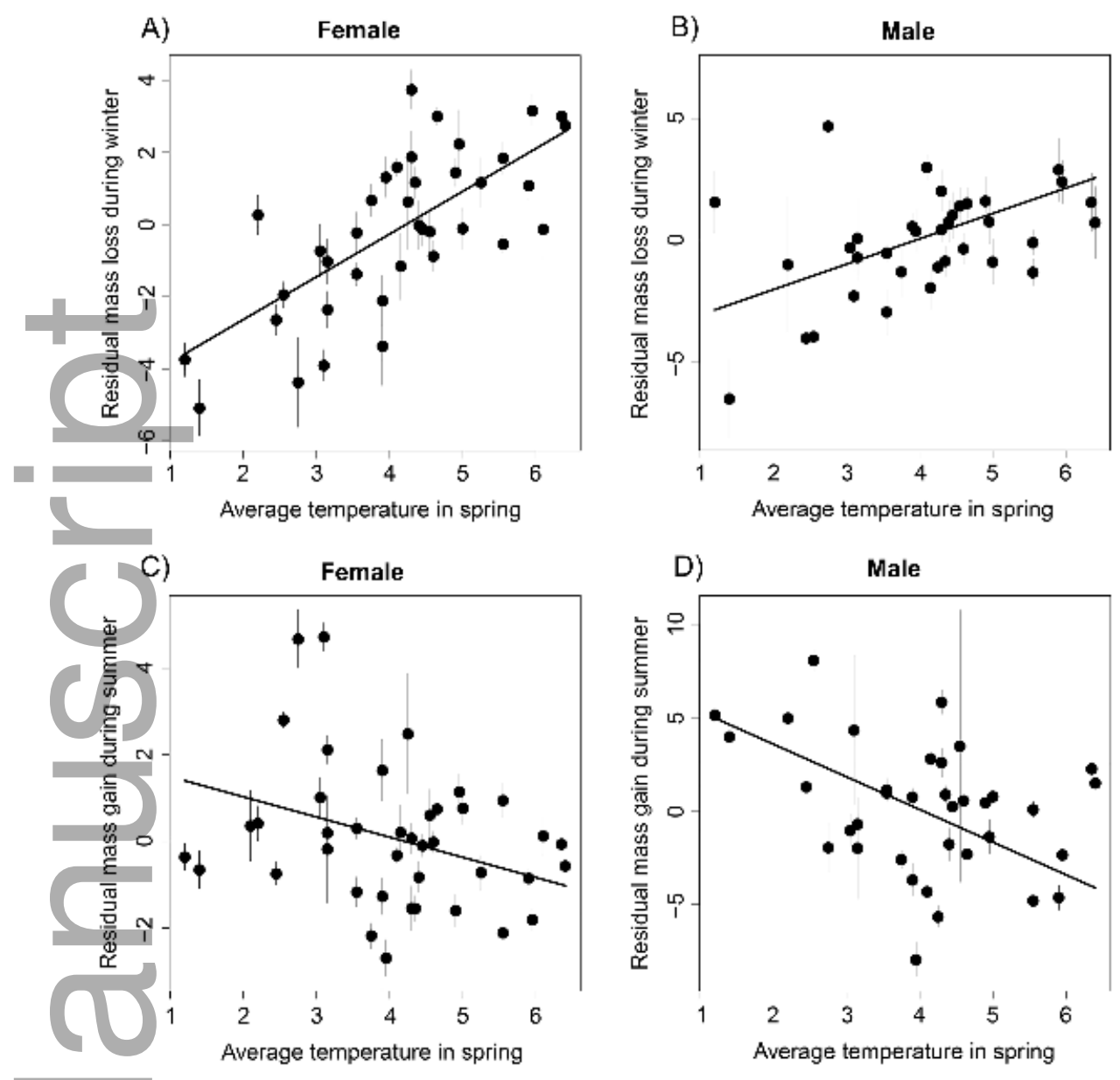

ecy_2141_f2.tif 


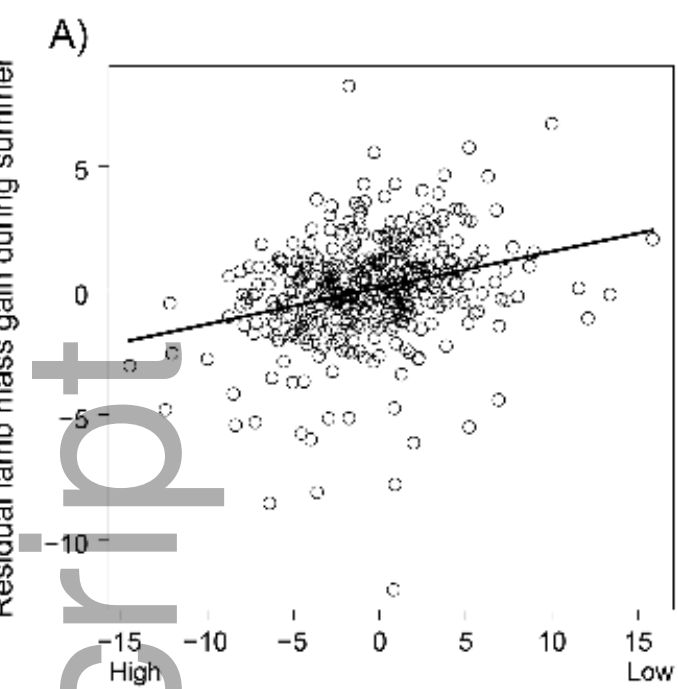

Maternal relative mass loss during winter
B)

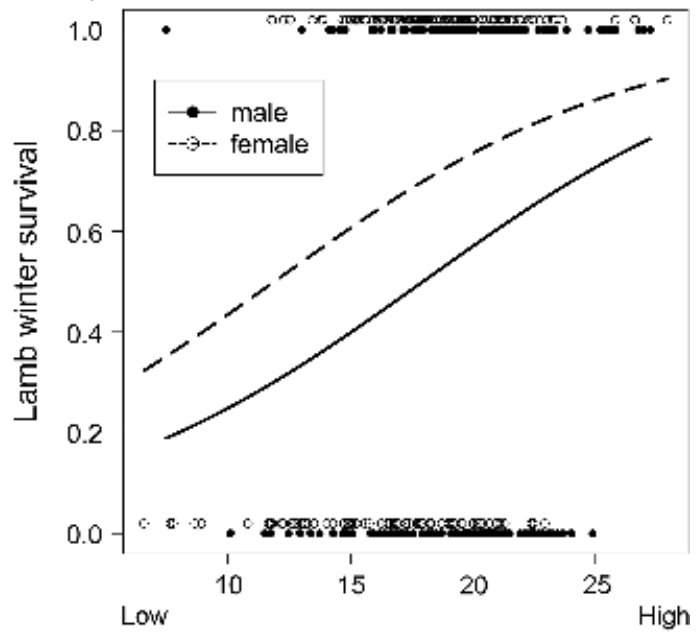

Absolute lamb mass gain during summer

ecy_2141_f3.tif

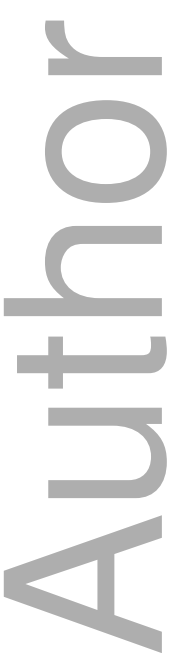

This article is protected by copyright. All rights reserved 


\section{University Library}

\section{- M M N E R VA A gateway to Melbourne's research publications}

Minerva Access is the Institutional Repository of The University of Melbourne

Author/s:

Douhard, M;Guillemette, S;Festa-Bianchet, M;Pelletier, F

Title:

Drivers and demographic consequences of seasonal mass changes in an alpine ungulate

Date:

2018-03-01

Citation:

Douhard, M., Guillemette, S., Festa-Bianchet, M. \& Pelletier, F. (2018). Drivers and demographic consequences of seasonal mass changes in an alpine ungulate. ECOLOGY, 99 (3), pp.724-734. https://doi.org/10.1002/ecy.2141.

Persistent Link:

http://hdl.handle.net/11343/283626 